\title{
Public Value, Psychology, and Neuroscience
}

\author{
Hyemin Han \\ Educational Psychology Program \\ University of Alabama
}

\begin{abstract}
Author Note
Hyemin Han @ \https://orcid.org/0000-0001-7181-2565

Correspondence concerning this article should be addressed to Hyemin Han, Box 870231, University of Alabama, Tuscaloosa AL 35487, United States of America. Email:
\end{abstract} hyemin.han@ua.edu 


\begin{abstract}
Research on public value is inevitably interdisciplinary in its nature due to its aim and purpose. Both philosophical and empirical approaches are necessary to conduct such research in a successful manner. In the present paper, I intend to discuss the importance of empirical approaches in research on public values, particularly psychological and neuroscientific approaches, with concrete examples. I proposed that such empirical approaches are essential in better understanding the processes and mechanisms associated with how people address issues associated with public value in the modern society. Also, I overviewed how the psychological and neuroscientific approaches contribute to practical aspects related to public value, such as policy making and education. Based on the aforementioned points, I briefly discussed directions for future research in research on public value as an interdisciplinary field.
\end{abstract}

Keywords: public value, psychology, neuroscience, psychological processes, policy making, education 


\section{Public Value, Psychology, and Neuroscience}

Research on which values should be pursued among the public and how to promote them in the reality, research on public value, should be multi- and/or interdisciplinary in its nature. For instance, on the one hand, if we are interested in composing a list of values that should be prioritized and emphasized among different groups of people, then we need to refer to philosophical accounts to justify such a list at least at the conceptual level (Bryson et al., 2015). On other hand, we also need to consider practical aspects related to research on public value as well (Meynhardt, 2009). Even if we have a list of values to be commonly pursued, which has been justified by philosophical and conceptual accounts, the mere presence of the list does not necessarily assure its successful implementation in the reality (Darnell et al., 2019). We can imagine several practical questions regarding the implementation of public value that cannot be easily answered by philosophical, abstract, and/or conceptual considerations. For example, practical ideas about how to persuade the public in an effective way to make the public endorse and implement the listed values could not be feasibly acquired solely by philosophical works (Hartley et al., 2017). Such a point suggests that empirical works are also essential in research on public value (Hartley et al., 2017; Meynhardt, 2009).

In this paper, given the aforementioned point regarding the necessity of empirical research on public value, I intend to review previous research in psychology and neuroscience relevant to public value. Previous empirical studies in the fields will be able to provide us with useful insights about the mechanisms associated with how people perceive and evaluate values and how to utilize various interventions in different settings to motivate people to accept and implement values in an effective way. Thus, reviewing psychological and neuroscientific studies relevant to public value would be worthwhile to improve research on public value as a field. To 
examine the aforementioned point, in this paper, I will two themes of studies in two fields, psychology and neuroscience. First, I intend to introduce previous empirical studies that examined human processes associated with public value at the psychological and neural levels.

Second, I will also overview prior research on the development of educational and psychological interventions to promote people's behavior implementing public value. Based on the overview of the relevant previous studies, I will briefly discuss how psychology and neuroscience can contribute to our endeavors to study public value.

\section{Potential contributions of psychological studies to research on public value}

Psychological and neuroscientific studies can provide useful insights about diverse values endorsed by the public based on evidence (e.g., Graham et al. 2011). In addition, empirical studies focusing on psychological and neural processes associated with values, such as how people perceive different values and how they differently response to them, can widen our understanding of public value (e.g., Emonds et al. 2011). Without further understanding of the aforementioned mechanisms or processes, it is impossible to design and implement interventions and policies to promote implementations of public value in the reality (Hartley et al., 2017). Hence, such previous studies in psychology and neuroscience would be useful resources when we start our interdisciplinary research on public value.

I shall overview psychological studies that particularly focused on describing value endorsement across diverse groups of people. In the field of moral psychology, which is primarily concerned about values and virtues, the moral foundations theory (MFT) that proposed by Graham et al. (2011) would be an exemplary theoretical framework showing how psychological works can contribute to describing diverse public values for their accurate understanding. According to the MFT, different people endorse and refer to different moral 
foundations while making a moral judgment or evaluation (e.g., Graham et al. 2009). The aforementioned foundations are care, fairness, ingroup/loyalty, authority/respect, and sanctity/purity (Graham et al., 2011). Before the emergence of the MFT, the majority of moral psychologists focused on the unidimensional aspect of morality, such as care vs. harm or fairness vs. cheating, instead of examining the diverse values endorsed by different groups (Haidt \& Graham, 2007; Han \& Dawson, 2021). When Graham et al. (2013) conducted their study by collecting data across different countries and cultures, they found that values endorsed by diverse populations could not be well explained by one dimension. Instead, they proposed that such values should be described in multiple dimensions, the five foundations proposed in the MFT. Since then, the MFT framework has enabled researchers in morality and values to acknowledge the diversity of values associated with morality across different groups of people in the globe. Of course, there have been criticisms to the MFT in the field as well. Gray and Keeney (2015) argued that four foundations other than care can be explained by one dimension, harm/care. Gray and Keeney's (2015) epistemological account proposes that different moral foundations are in fact diversification of the primary dimension, harm/care, in different contexts. Also, moral psychologists who were interested in normative and prescriptive aspects of morality have also argued that the MFT is not capable of producing meaningful norms or prescriptions although it significantly contributed to describing human morality. For instance, in line with Gray and Keeney's (2015) argument at the epistemological level, Han and Dawson (2021) reported that sophisticated moral reasoning was positively associated with individualizing foundations, care and fairness, not binding foundations, ingroup/loyalty, authority/respect, and sanctity/purity. Hence, from these critiques, we can see that although a theory might well describe different values and their endorsement across different groups, it could not be very 
informative in inquiries regarding normative or prescriptive aspects of morality (e.g., Blum, 2013).

Despite the aforementioned limitations, descriptive works in psychology, such as what the MFT have done, will be able to inform our research on public value in the long run. One of the most significant contributions is that MFT researchers demonstrated the differences in endorsed values across people with different political orientations (e.g., liberal vs. conservative, religious orientations, etc.) that had not been well studied (Graham et al., 2009; Haidt \& Graham, 2007). Such findings informed Haidt's (2012) further examination regarding how to address severe value-related conflicts between people with different orientations occurring in the modern society. Although the MFT and other descriptive studies on values would not be able to provide significant normative or prescriptive implications in a direct manner, the aforementioned case suggests that such descriptive works can provide researchers and policy makers with basic data about the current status so that they can invent effective practical solutions to address social issues related to values.

Moreover, a recent psychological study has proposed an effective psychological intervention using personal experiences to address the severe political polarization associated with conflicts between values. Kubin et al. (2021) demonstrated that conflicts originating from the endorsement of different values between participants with different political orientations can be better addressed by sharing concrete personal experiences instead of presenting factual information. This line of research would provide us with some considerable solutions that can practically address conflicts between people endorsing different political views, and finally, different values based on empirical evidence. As shown in the previously introduced exemplary psychological studies, empirical studies in psychology addressing morality and values can help 
us better describe diverse values existing and endorsed across diverse groups of people and explore potential solutions to address value-involved conflicts.

\section{Potential Contributions of Neuroscientific Studies to Research on Public Value}

In addition to the aforementioned psychological works regarding public value, studies in neuroscience that address the psychological and neural processes associated with how such values are perceived and processed can also provide us with useful insights (Han, 2019; Han et al., 2019; Illes et al., 2010; Kelly \& O’Connell, 2020). Particularly, research on such processes is informative while considering practical solutions to address conflicts between different groups endorsing different sets of values in modern society where has been highly diversified (e.g., Greene, 2013).

Among previous neuroscientific studies, we may refer to works done by Greene (2009) that proposed the dual process model regarding how a human brain addresses dilemmas associated with morality and values. In their original neuroimaging study, Greene et al. (2001) reported that two distinctive psychological processes, cognitive and affective processes, are activated while solving moral dilemmas. When people are dealing with moral dilemmas that directly present concrete harms to people (i.e., moral-personal dilemmas), brain regions associated with affective processes, such as the ventromedial prefrontal cortex, showed significant activity. On the other hand, when they were solving hypothetical moral dilemmas (i.e., moral-impersonal dilemmas), brain regions correlated with cognitive and arithmetic processes were significantly activated. From the findings, Greene (2009) proposed the dual process model that describes two distinctive cognitive and affective pathways in value-engaged problem solving (May et al., 2021). When people are addressing relatively simple problems involving only minimal conflicts, they can utilize the affective processes implementing heuristics 
to save time and energy. However, when they encounter complicated problems, the activation of the slower cognitive processes for sophisticated reasoning becomes necessary.

The model would show us different psychological processes involving solution of valuerelated problems with different degrees of complexity at the neural level. Additionally, Greene (2013) emphasized the role of reasoning-based processes to address complicated conflicts between values endorsed by different groups of people based on the model. In fact, Haidt (2012) also proposed measures to address such conflicts. The measures were based on assumptions, which were different from Greene's (2013), such as the multitude of values and importance of intuitive processes in judgment proposed in the MFT (Graham et al., 2011). Unlike Haidt (2012), Greene (2013) suggested several prescriptive guidelines underscoring the roles of reasoning, instead of intuition, in conflict solving based on the dual process model based on neuroimaging evidence. Of course, there have been critiques to the validity of Greene's $(2009,2013)$ accounts raised by moral philosophers (e.g., Königs, 2018). Despite the criticisms, at least, we may acknowledge potential values of neuroimaging works in consideration of prescriptive and practical solutions to address issues associated with conflicts between values in the highly diversified modern society.

Furthermore, related to educational programs for the promotion of public value, previous research in neuroscience would provide us with useful insights about how to improve the effectiveness of such programs in class settings (Han, 2019). Even if people understand that certain values should be endorsed and pursued, they do not necessary implement such values in their actual behavior. As discussed by Darnell et al. (2019), the gappniess issue, which is about the gap between one's belief and behavior, has been one of the major issues in moral education 
and psychology (Blasi, 1980; Han, 2014). Hence, we need to consider how to address the gappiness in promoting public value, particularly its behavioral implementations.

A recent work in educational neuroscience that focused on the neural correlates of moral functioning, and developed and tested an educational intervention based on the findings from the neural-level investigations would be informative for the aforementioned consideration (Han et al., 2019). As an example, we may overview a moral educational intervention using different types of the stories of exemplars (Han et al., 2017). Because moral exemplars present moral values that shall be pursued and implemented in actions with concrete behavioral examples, presenting the stories of such exemplars has been regarded as one of major educational methods in moral education (Damon \& Colby, 2013). Such an approach is particularly supported by the perspective of social learning, which emphasizes roles of models in promoting motivation for imitation and emulation (Bandura \& McDonald, 1963; Sanderse, 2012). However, Monin (2007) and Monin et al. (2008) reported that the mere presentation of exemplary stories, particularly the stories of distant exemplars that are perceived to be extraordinary and non-relatable to people, may backfire. Such extreme stories are likely to produce negative emotional and motivational responses instead of motivation for emulation.

To address the aforementioned issue, Han et al. (2017) examined which types of exemplary stories would work more effectively while minimizing the potential negative outcomes. To develop an effective psychological intervention, it is important to identify which psychological processes are closely involved in the targeted outcomes, i.e., motivational and behavioral outcomes (Walton, 2014; Yeager \& Walton, 2011). Thus, as an effort to identify the processes, Han (2017) conducted meta-analysis of the previous fMRI studies related to moral functioning and Han et al. (2016) conducted an fMRI experiment examining the interaction 
between brain regions associated with selfhood and moral emotion and motivation. According to Han et al. (2016), these findings suggested the close association between one's selfhood and moral motivation in general (Boccia et al., 2016; Englander et al., 2012; Garrigan et al., 2016; Han, 2020). Based on the results from the neuroimaging studies, Han et al., (2017) examined whether the closeness of the presented exemplars to participants (e.g., whether the exemplars are perceived to be attainable and relatable) influenced moral motivation when exemplary stories were presented. As hypothesized, they reported that the stories of close moral exemplars, such as family members and friends, more effectively promoted motivation to engage in voluntary activities compared with the stories of distant exemplars, such as historic figures. In short, the findings from the intervention study suggest that the perceived connectivity between the presented exemplars and participants significantly influence the motivational outcome of the intervention, so this point might need to be considered while designing effective programs for moral education using exemplary stories.

This concrete example in moral education may demonstrate how findings from neuroimaging studies can inform the development of interventions to promote moral values in educational settings. As shown, neuroscientific research focusing on psychological processes associated with values and virtues can inform us, who are interested in developing effective interventions, which processes should be aimed in the interventions (Han et al., 2019; Kelly \& O’Connell, 2020). Likewise, at the practical level, neuroscience can make significant contributions to designing educational programs and policies to promote desirable public value with empirical evidence (Han et al., 2019).

\section{Concluding Remarks}


So far, in this paper, I have briefly reviewed several previous psychological and neuroscientific studies that addressed topics related to public value. Particularly, I have focused on research in describing values shared across different groups of people and how to address conflicts regarding diverse values in a more effective way. In addition, I also reviewed previous studies related to how to promote values and virtues among people through education in an effective way. Although findings from previous studies in psychology and neuroscience per se would not be able to provide us with complete answers to our questions about norms and prescriptions, which can perhaps be better addressed by moral philosophy, at the practical level, they can provide useful insights about how to better understand processes associated with public value and how to promote them through education and policy making. Hence, we need to promote interdisciplinary collaboration embracing philosophical and empirical works addressing public value to improve research on public value in the long term.

\section{References}

Bandura, A., \& McDonald, F. J. (1963). Influence of social reinforcement and the behavior of models in shaping children's moral judgments. Journal of Abnormal and Social Psychology, 67(3), 274-281.

Blasi, A. (1980). Bridging moral cognition and moral action: A critical review of the literature. Psychological Bulletin, 88, 1-45. https://doi.org/10.1037/0033-2909.88.1.1

Blum, L. (2013). Political identity and moral education: A response to Jonathan Haidt's The Righteous Mind. Journal of Moral Education, 42(3), 298-315. https://doi.org/10.1080/03057240.2013.817331

Boccia, M., Dacquino, C., Piccardi, L., Cordellieri, P., Guariglia, C., Ferlazzo, F., Ferracuti, S., \& Giannini, A. M. (2016). Neural foundation of human moral reasoning: an ALE meta- 
analysis about the role of personal perspective. Brain Imaging and Behavior. https://doi.org/10.1007/s11682-016-9505-x

Bryson, J. M., Crosby, B. C., \& Bloomberg, L. (2015). Discerning and Assessing Public Value. In J. M. Bryson, B. C. Crosby, \& L. Bloomberg (Eds.), Public Value and Public Administration (p. 1). Georgetown University Press.

Damon, W., \& Colby, A. (2013). Why a true account of human development requires exemplar research. In M. K. Matsuba, P. E. King, \& K. C. Bronk (Eds.), Exemplar methods and research: Quantitative and qualitative strategies for investigation. New Directions in Child and Adolescent Development (pp. 13-26). Jossey-Bass.

Darnell, C., Gulliford, L., Kristjánsson, K., \& Paris, P. (2019). Phronesis and the KnowledgeAction Gap in Moral Psychology and Moral Education: A New Synthesis? Human Development, 62(3), 101-129. https://doi.org/10.1159/000496136

Emonds, G., Declerck, C. H., Boone, C., Vandervliet, E. J. M., \& Parizel, P. M. (2011). Comparing the neural basis of decision making in social dilemmas of people with different social value orientations, a fMRI study. Journal of Neuroscience, Psychology, and Economics, 4(1), 11-24. https://doi.org/10.1037/a0020151

Englander, Z. A., Haidt, J., \& Morris, J. P. (2012). Neural basis of moral elevation demonstrated through inter-subject synchronization of cortical activity during free-viewing. Plos One, 7(6), e39384. https://doi.org/10.1371/journal.pone.0039384

Garrigan, B., Adlam, A. L. R., \& Langdon, P. E. (2016). The neural correlates of moral decisionmaking: A systematic review and meta-analysis of moral evaluations and response decision judgements. Brain and Cognition, 108, 88-97. https://doi.org/10.1016/j.bandc.2016.07.007 Graham, J., Haidt, J., Koleva, S., Motyl, M., Iyer, R., Wojcik, S. P., \& Ditto, P. H. (2013). Moral 
Foundations Theory. Advances in Experimental Social Psychology, 47, 55-130. https://doi.org/10.1016/B978-0-12-407236-7.00002-4

Graham, J., Haidt, J., \& Nosek, B. A. (2009). Liberals and conservatives rely on different sets of moral foundations. Journal of Personality and Social Psychology, 96(5), 1029-1046. https://doi.org/10.1037/a0015141

Graham, J., Nosek, B. A., Haidt, J., Iyer, R., Koleva, S., \& Ditto, P. H. (2011). Mapping the moral domain. Journal of Personality and Social Psychology, 101(2), 366-385. https://doi.org/10.1037/a0021847

Gray, K., \& Keeney, J. E. (2015). Disconfirming Moral Foundations Theory on Its Own Terms. Social Psychological and Personality Science, 6(8), 874-877. https://doi.org/10.1177/1948550615592243

Greene, J. D. (2009). The Cognitive Neuroscience of Moral Judgment. Neuroscience, 987-1003. Greene, J. D. (2013). Moral Tribes: Emotion, Reason, and the Gap Between Us and Them. Penguin Book.

Greene, J. D., Sommerville, R. B., Nystrom, L. E., Darley, J. M., \& Cohen, J. D. (2001). An fMRI investigation of emotional engagement in moral judgment. Science, 293(5537), 21052108. https://doi.org/10.1126/science. 1062872

Haidt, J. (2012). The righteous mind: Why good people are divided by politics and religion. Pantheon Books.

Haidt, J., \& Graham, J. (2007). When Morality Opposes Justice: Conservatives Have Moral Intuitions that Liberals may not Recognize. Social Justice Research, 20(1), 98-116. https://doi.org/10.1007/s11211-007-0034-z

Han, H. (2014). Analyzing theoretical frameworks of moral education through Lakatos's 
philosophy of science. Journal of Moral Education, 43(1), 32-53.

https://doi.org/10.1080/03057240.2014.893422

Han, H. (2017). Neural correlates of moral sensitivity and moral judgment associated with brain circuitries of selfhood: A meta-analysis. Journal of Moral Education, 46(2), 97-113. https://doi.org/10.1080/03057240.2016.1262834

Han, H. (2019). Neuroscience of Morality and Teacher Education. In M. A. Peters (Ed.), Encyclopedia of Teacher Education. Springer Singapore. https://doi.org/10.1007/978-98113-1179-6_190-1

Han, H. (2020). Comment on Raine (2019) 'The neuromoral theory of antisocial, violent, and psychopathic behavior' [version 2; peer review: 2 approved, 1 not approved]. F1000Research, 9, 274. https://doi.org/10.12688/f1000research.23346.2

Han, H., Chen, J., Jeong, C., \& Glover, G. H. (2016). Influence of the cortical midline structures on moral emotion and motivation in moral decision-making. Behavioural Brain Research, 302, 237-251. https://doi.org/10.1016/j.bbr.2016.01.001

Han, H., \& Dawson, K. J. (2021). Improved model exploration for the relationship between moral foundations and moral judgment development using Bayesian Model Averaging. Journal of Moral Education. https://doi.org/10.1080/03057240.2020.1863774

Han, H., Kim, J., Jeong, C., \& Cohen, G. L. (2017). Attainable and Relevant Moral Exemplars Are More Effective than Extraordinary Exemplars in Promoting Voluntary Service Engagement. Frontiers in Psychology, 8, 283. https://doi.org/10.3389/fpsyg.2017.00283

Han, H., Soylu, F., \& Anchan, D. M. (2019). Connecting Levels of Analysis in Educational Neuroscience: A Review of Multi-level Structure of Educational Neuroscience with Concrete Examples. Trends in Neuroscience and Education, 100113. 
https://doi.org/10.1016/j.tine.2019.100113

Hartley, J., Alford, J., Knies, E., \& Douglas, S. (2017). Towards an empirical research agenda for public value theory. Public Management Review, 19(5), 670-685. https://doi.org/10.1080/14719037.2016.1192166

Illes, J., Moser, M. A., McCormick, J. B., Racine, E., Blakeslee, S., Caplan, A., Hayden, E. C., Ingram, J., Lohwater, T., McKnight, P., Nicholson, C., Phillips, A., Sauvé, K. D., Snell, E., \& Weiss, S. (2010). Neurotalk: improving the communication of neuroscience research. Nature Reviews Neuroscience, 11(1), 61-69. https://doi.org/10.1038/nrn2773

Kelly, C., \& O'Connell, R. (2020). Can Neuroscience Change the Way We View Morality? Neuron, 108(4), 604-607. https://doi.org/10.1016/j.neuron.2020.10.024

Königs, P. (2018). On the normative insignificance of neuroscience and dual-process theory. Neuroethics, 11(2), 195-209. https://doi.org/10.1007/s12152-018-9362-y

Kubin, E., Puryear, C., Schein, C., \& Gray, K. (2021). Personal experiences bridge moral and political divides better than facts. Proceedings of the National Academy of Sciences, 118(6), e2008389118. https://doi.org/10.1073/pnas.2008389118

May, J., Workman, C. I., Haas, J., \& Han, H. (2021). The Neuroscience of Moral Judgment: Empirical and Philosophical Developments. In F. De Brigard \& W. Sinnott-Armstrong (Eds.), Neuroscience and Philosophy (pp. 17-47). MIT Press.

Meynhardt, T. (2009). Public Value Inside: What is Public Value Creation? International Journal of Public Administration, 32(3-4), 192-219. https://doi.org/10.1080/01900690902732632

Monin, B. (2007). Holier than me? Threatening social comparison in the moral domain. Revue Internationale de Psychologie Sociale, 20(1), 53-68. 
Monin, B., Sawyer, P. J., \& Marquez, M. J. (2008). The rejection of moral rebels: resenting those who do the right thing. Journal of Personality and Social Psychology, 95, 76-93. https://doi.org/10.1037/0022-3514.95.1.76

Sanderse, W. (2012). The meaning of role modelling in moral and character education. In Journal of Moral Education (pp. 1-15). https://doi.org/10.1080/03057240.2012.690727

Walton, G. (2014). The New Science of Wise Psychological Interventions. Current Directions in Psychological Science, 23. https://doi.org/10.1177/0963721413512856

Yeager, D. S., \& Walton, G. M. (2011). Social-psychological interventions in education: They're not magic. Review of Educational Research, 81(2), 267-301.

https://doi.org/10.3102/0034654311405999 